\title{
Bioaccessibility of bioactive compounds and antioxidant capacity from orange peel after pulsed electric fields and high voltage electrical discharges
}

\begin{abstract}
In the present study changes of bioactive compounds and antioxidant capacity in orange peel treated by pulsed electric fields (PEF), high voltage electrical discharges (HVED) at two equivalent energy inputs $(55-364 \mathrm{~kJ} / \mathrm{kg})$ as well as relative bioaccessibility was evaluated. PEF treatment led to decrease in ascorbic acid when energy input increased. Moreover TPC after PEF and HVED treatments increased significantly with higher energy input applied. By contrast, HVED at $364 \mathrm{~kJ} / \mathrm{kg}$ diminished carotenoids content.

The relative bioaccessibility of carotenoids after HVED $(55 \mathrm{~kJ} / \mathrm{kg})$ was $75.3 \%$. When increasing the energy input from 55 to $364 \mathrm{~kJ} / \mathrm{kg}$ in HVED the bioaccessibility percentage of carotenoids increased in a $82.5 \%$. On the other hand TPC bioaccessibility for PEF at lower energy input was $40.7 \%$. However increasing the energy input to $364 \mathrm{~kJ} / \mathrm{kg}$ led to decrease of the TPC independently of treatment applied. Consequently, results indicated that non thermal treatments such as (PEF, HVED) can enhance the release of bioactive compounds and total antioxidant capacity after in vitro gastrointestinal digestion in orange peel. However, further research is required tooptimize processing conditions.
\end{abstract}

Keywords: high voltage electrical discharges, pulsed electric fields, bioaccessibility, bioactive compounds, antioxidant activity
Volume I Issue 3 - 2015

Buniowska M, Carbonell-Capella J, Zulueta A, Frigola A, Esteve MJ

Nutrition and Food Science, Universitat de València, Spain

Correspondence: Maria J Esteve, Nutrition and Food Science, Facultad de Farmacia, Universitat de Valencia,Avda.Vicent Andres Estelles, s/n 46100 Burjassot (Valencia), Tel +34 96354 49|3, Fax +34 96354 4954, Email maria.jose.esteve@uv.es

Received: October 23, 2015 | Published: October 30, 2015
Abbreviations: TPC, total phenolic content; TC, total carotenoids; TEAC, trolox equivalent antioxidant capacity; ORAC, oxygen radical antioxidant capacity; PEF1, pulsed electric fields $(55 \mathrm{~kJ} / \mathrm{kg}) ;$ PEF2, pulsed electric fields $(364 \mathrm{~kJ} / \mathrm{kg}) ;$ HVED1, high voltage electrical discharges $(55 \mathrm{~kJ} / \mathrm{kg}) ; \mathrm{HVED} 2$, high voltage electrical discharges $(364 \mathrm{~kJ} / \mathrm{kg})$

\section{Introduction}

Traditionally, food wastes have been considered as a problem However, they could be a great source of valuable nutraceuticals which can be used to deal with the prospects of feeding fast growing population in $21^{\text {st }}$ century. Perspectives originate from the enormous amounts of food related materials that are discharged worldwide and the existing technologies, which promise the recovery, recycling and sustainability of high-added value ingredients inside food chain.

In this line, a great amount of citric wastes and by-products are generated each year in Europe. Orange peels, which are by-products of orange processing, are a good source of bioactive compounds, such as phenolic content, carotenoids, and vitamin $\mathrm{C}$, which can be used as food additives and/or nutraceuticals. ${ }^{1-4}$ Several epidemiological studies suggest that bioactive compounds have beneficial effects and have been involved in the reduction of degenerative diseases such as cancers of the lungs and alimentary tract, being this effect mainly attributed to their antioxidant capacity. ${ }^{5-6}$

Conventional extraction methods used for the recovery of bioactive compounds are based on maceration and heat extraction at temperatures $>60^{\circ} \mathrm{C}$ alone and/or combined with different solvents, which can be toxic (i.e., hexane, acetone, methanol, etc.). Moreover, the use of high temperatures can promote nutritional losses. ${ }^{7-8}$ At this stage of development, there is a need to develop new extraction methods that can reduce the extraction time, temperature and solvent consumption and contribute to higher extraction efficiency and lower energy consumption as compared to conventional extraction techniques.

For instance, pulsed electric fields (PEF) and high voltage electrical discharges (HVED) can be useful tools to recover bioactive compounds from fruit by-products. Recent scientific and practical efforts have shown full correspondence of pulsed electric fields (PEF) techniques with green extraction concept. ${ }^{9}$ This concept assumes using renewable plant resources and alternative solvents (water or agro-solvents (ethanol, methyl esters of fatty acids of vegetable oils)), reduction of energy consumption and unit operations, production of high quality and purity of extracts (non-denatured and biodegradable) and extracts co-products instead of wastes. ${ }^{10}$ Moreover, methods assisted by pulsed electric energy can allow the increase of the yield and quality of the extracted compounds, thus decreasing the time and temperature of extraction operations. ${ }^{11-17}$

Some previous studies have evaluated the effectiveness of pulsed electric fields on antioxidant compounds recovery from orange peel ${ }^{15}$ but there are no studies evaluating the impact of non-thermal treatments (PEF and HVED) upon the bioaccessibility of orange peel thorought a simulated in vitro digestion. Bioaccessibility has been defined as the fraction of a compound released from the food matrix in the gastrointestinal tract and thus available for intestinal absorption. ${ }^{18}$ This parameter provides valuable information in order to select the appropriate dosage and source of food matrices as bioactive 
compounds. Thus, the objectives of this work were 1) to determine the recovery of bioactive compounds (ascorbic acid, phenolic content and carotenoids) and antioxidant capacity (TEAC and ORAC) from orange peel immediately after pulsed electric fields and high voltage electrical discharges treatments and 2) to evaluate the bioaccessibility of the extracted compounds through a simulated in vitro digestion.

\section{Material and methods}

\section{Samples}

The orange peels were obtained from orange fruits (Navel lanelate) purchased at a local supermarket (Castellón, Spain) and used immediately. The orange peels were removed from the pulp and chopped into square pieces of $5 \pm 1 \mathrm{~mm}^{2}$.

\section{Treatments}

A pulsed high voltage power supply (Tomsk Polytechnic University, Tomsk, Russia) that provided 40kV-10 kA discharges for a few microseconds $(\approx 10 \mu \mathrm{s})$ was used for electrical treatments. For PEF, the stainless electrodes of the 1-L treatment chamber were two parallel disks. The electrode area was $95 \mathrm{~cm}^{2}$. The distance between the electrodes can be varied from 1 to $10 \mathrm{~cm}$. The circuit configuration and the electrodes shape generated exponential decay pulses. The PEF pulse length was about $\mathrm{t}_{\mathrm{i}}=10 \mu \mathrm{s}$, and the electric field was $13.3 \mathrm{kV}$ / $\mathrm{cm}$. For HVED, the $1-\mathrm{L}$ treatment chamber (inner diameter $=10 \mathrm{~cm}$, wall thickness $=2.5 \mathrm{~cm}$ ) was equipped with needle-plate geometry electrodes. The diameters of stainless steel needle and the grounded disk electrodes were 10 and $35 \mathrm{~mm}$ respectively. The distance between the electrodes was $5 \mathrm{~mm}$. Energy was stored in a set of low-inductance capacitors, which were charged by the high-voltage power supply. The electrical discharges were generated by electrical breakdown in water at the peak pulse voltage (U) of $40 \mathrm{kV}$. Damped oscillations were thus obtained over a total duration $\mathrm{t}_{\mathrm{i}}$ of $\approx 10 \mu \mathrm{s}$. The voltage (Ross VD45-8.3-A-K-A, Ross Engineering Corp., Campbell, California, USA) and current (Pearson 3972, Pearson Electronics Inc., Campbell, California, USA) measurement units were connected with a $108 \mathrm{~Hz}$ sampling system via an oscilloscope (Tektronix TDS1002, Beaverton, Oregon, USA). The software HPVEE 4.01 (Hewlett-Packard, Palo Alto, USA) was used for data acquisition.

The total treatment duration, $t_{t},\left(t_{t}=\mathrm{n} \times t_{P E F / H V E D}\right)$ was changed by increasing the number of pulses $n$ from 50 to 400 . The specific energy input $\mathrm{W}(\mathrm{kJ} / \mathrm{kg})$ was obtained from Eq. 1:

$$
W=\frac{\sum_{i=1}^{n} W_{P E F / H V E D}}{m}
$$

where $\mathrm{W}_{\text {PEF/HVED }}$ is the pulse energy ( $\mathrm{kJ} /$ pulse), and $\mathrm{m}$ is the product mass $(\mathrm{kg}) . \mathrm{W}_{\mathrm{PEF} / \mathrm{HVED}}$ is determined from Eq. 2:

$$
W_{P E F / H V E D}=\int_{0}^{t} U \times I \times d t \quad \underline{(2)}
$$

where $U$ is the voltage $(\mathrm{V})$ and $\mathrm{I}$ is the current strength (A), which corresponded to energy inputs of $55 \mathrm{~kJ} / \mathrm{kg}$ (PEF 1/HVED1) and 364kJ/ $\mathrm{kg}$ (PEF 2/HVED2).

\section{Ascorbic content}

Ascorbic acid was assayed by polarographic determination using a Metrohm 746VA Trace Analyzer (Herisau, Switzerland) equipped with a Metrohm 747VA stand. The working electrode was a Metrohm multi-mode electrode operated in the dropping mercury mode. A platinum wire counter electrode and a saturated calomel reference electrode were used. The following instrumental conditions were applied: DP50, mode DME, drop size 2, drop time 1s, scan rate $10 \mathrm{mV} / \mathrm{s}$, initial potential $-0.10 \mathrm{~V}$. Samples $(5 \mathrm{~mL})$ were diluted to $25 \mathrm{~mL}$ with the extraction solution (oxalic acid $1 \% \mathrm{w} / \mathrm{v}$, trichloroacetic acid $2 \% \mathrm{w} / \mathrm{v}$, sodium sulfate $1 \%(\mathrm{w} / \mathrm{v})$. After vigorous shaking, the solution was filtered through a folded filter (Whatman No.1). Oxalic acid $(9.5 \mathrm{~mL}) 1 \%(\mathrm{w} / \mathrm{v})$ and $2 \mathrm{ml}$ of acetic acid/sodium acetate $2 \mathrm{M}$ buffer $(\mathrm{pH}=4.8)$ were added to an aliquot of $0.5 \mathrm{~mL}$ of filtrate and the solution was transferred to the polarographic cell. Determinations were carried out by using the peak height and standard addition method in accordance to Carbonell-Capella et al. ${ }^{19}$

\section{Total phenolic content}

Total phenols were determined using a modified method of Georgé et al., ${ }^{20}$ with some modifications. $10 \mathrm{~mL}$ of sample were homogenised with $50 \mathrm{~mL}$ of a mixture of acetone/water $(7 / 3, \mathrm{v} / \mathrm{v})$ for $30 \mathrm{~min}$. Mixture supernatants were then recovered by filtration (Whatman ${ }^{\circledR}$ No.2, England) and constituted the raw extracts (REs). REs $(2 \mathrm{~mL})$ were settled on an Oasis cartridge (Waters). Interfering water-soluble components (ascorbic acid and reducing sugars) were recovered with $2 \times 2 \mathrm{~mL}$ of distilled water. The recovered volume of the washing extract (WE) was carefully measured. In order to eliminate vitamin $\mathrm{C}$, heating was carried out on the washing extract (HWE). All extracts (RE, WE, and HWE) were submitted to the Folin-Ciocalteu method, adapted and optimised..$^{21}$ Gallic acid calibration standards with concentrations of $0,100,300,500,700$ and $1000 \mathrm{ppm}$ were prepared and $0.1 \mathrm{~mL}$ was transferred to borosilicate tubes. $3 \mathrm{~mL}$ of sodium carbonate solution $(2 \% \mathrm{w} / \mathrm{v})$ and $100 \mu \mathrm{L}$ of Folin-Ciocalteau reagent $(1: 1, \mathrm{v} / \mathrm{v})$ were added to $100 \mu \mathrm{L}$ of all gallic acid standard and sample tubes. The mixture was incubated for $1 \mathrm{~h}$ at room temperature and absorbance was measured at $765 \mathrm{~nm}$.

\section{Total carotenoids}

Extraction of total carotenoidwas carried out in accordance with Lee et al. ${ }^{22}$ An aliquot of sample $(2 \mathrm{~mL})$ was homogenized with $5 \mathrm{~mL}$ of extracting solvent (hexane/acetone/ethanol, 50:25:25/v) and centrifuged for $5 \mathrm{~min}$ at $4000 \mathrm{rpm}$ at $5^{\circ} \mathrm{C}$. The top layer of hexane containing the colour was recovered and transferred to a $5 \mathrm{~mL}$ volumetric flask and the volume was then adjusted to $25 \mathrm{~mL}$ with hexane. Total carotenoid determination was carried out on an aliquot of the hexane extract by measuring the absorbance at $450 \mathrm{~nm}$. Total carotenoids were calculated according to Ritter et al. ${ }^{23}$ using an extinction coefficient of $\beta$-carotene, $\mathrm{E}^{1 \%}=2505$.

\section{TEAC assay}

The method used was described by Re et al. ${ }^{24}$ based on the capacity of a sample to inhibit the ABTS radical $\left(\mathrm{ABTS}^{++}\right.$) (SigmaAldrich, Steinheim, Germany) compared with a reference antioxidant standard (Trolox $\AA$ ) (Sigma-Aldrich, Steinheim, Germany). The radical was generated using $440 \mu \mathrm{L}$ of potassium persulfate $(140$ $\mathrm{mM}$ ). The solution was diluted with ethanol (Baker, Deventer, The Netherlands) until an absorbance of 0.70 was reached at $734 \mathrm{~nm}$. Once the radical was formed, $2 \mathrm{~mL}$ of $\mathrm{ABTS}^{++}$was mixed with $100 \mu \mathrm{L}$ of 
appropriately diluted sample and the absorbance was measured at $734 \mathrm{~nm}$ for $20 \mathrm{~min}$ in accordance with TCarbonell-Capella et al. ${ }^{19}$ he results, obtained from duplicate analyses, were expressed as: $\mathrm{mM} \mathrm{TE}$ (millimolar Trolox equivalents).

\section{ORAC assay}

The oxygen radical absorbance capacity (ORAC) assay used, with fluorescein as the "fluorescent probe", was that described by Barba et al. ${ }^{21}$ The automated ORAC assay was carried out on a Wallac 1420 VICTOR X3 multilabel counter (Perkin-Elmer, USA) with fluorescence filters, for an excitation wavelength of $485 \mathrm{~nm}$ and an emission wavelength of $535 \mathrm{~nm}$. The measurements were made in plates with 96 white flat bottom wells (Sero-Wel, BibbySterilin Ltd., Stone, UK). The reaction was performed at $37^{\circ} \mathrm{C}$, as the reaction was started by thermal decomposition of AAPH in $75 \mathrm{mM}$ phosphate buffer ( $\mathrm{pH} 7.0)$.

\section{Simulated digestion}

A three-stage in vitro digestion model was performed based on the previously described procedure by Rodríguez-Roque et al. ${ }^{25}$ with some modification(the addition of a salivary step). Briefly, $50 \mathrm{~mL}$ of each sample(in triplicate) was transferred to an Erlenmeyer flask, and a saliva solution $(5 \mathrm{~mL}$, pH $6.75 \pm 0.20)$ containing $2.38 \mathrm{~g} \mathrm{Na}_{2} \mathrm{HPO}_{4}$, $0.19 \mathrm{~g} \mathrm{KH}_{2} \mathrm{PO}_{4}, 8 \mathrm{~g} \mathrm{NaCl}, 100 \mathrm{mg}$ of mucin and $\alpha$-amylase $(200 \mathrm{U} / \mathrm{L}$ of enzyme activity) in $1 \mathrm{~L}$ of distilled water was added. This mixture was kept in a shaking water bath $\left(37^{\circ} \mathrm{C}, 90 \mathrm{rpm}\right)$ for $10 \mathrm{~min}$. Afterwards, $13.08 \mathrm{mg}$ of pepsin from porcine stomach was added and $\mathrm{pH}$ was adjusted to 2 by addition of $\mathrm{HCl}(12 \mathrm{M})$. This mixture was incubated in darkness in a water bath at $37^{\circ} \mathrm{C}$ with continuous stirring (90rpm) for 2 hours. At the end of the gastric digestion, aliquots were taken for analysis and $20 \mathrm{~mL}$ were used for titration with $\mathrm{NaOH}(0.5 \mathrm{M})$ to $\mathrm{pH}$ 7.5 after adding $5 \mathrm{ml}$ of pancreatin $(4 \mathrm{~g} / \mathrm{L})$ - bile $(25 \mathrm{~g} / \mathrm{L})$ mixture.

Dialysis membrane was aconditionated with $0.01 \mathrm{M}$ EDTA $\mathrm{Na}_{2}$, $2 \% \mathrm{NaHCO}_{3}$ and $0.1 \%$ sodium dodecyl sulfate at boiling point, rinsed with distilled water and cut into segments of $30 \mathrm{~cm}$. Dialysis membrane segments were filled with $25 \mathrm{~mL}$ of water- $\mathrm{NaHCO}_{3}$ mixture, with the amount of $\mathrm{NaHCO}_{3}(0.5 \mathrm{~N})$ used in the previous titration. $20 \mathrm{~mL}$ of the gastric digest were placed into a beaker and the dialysis membrane was immersed in that digest until reaching $\mathrm{pH}$ 5.0. This process allows gradual $\mathrm{pH}$ adjustment, mimicking intestinal conditions. After $30 \mathrm{~min}, 5 \mathrm{~mL}$ of pancreatin $(4 \mathrm{~g} / \mathrm{L})$-bile $(25 \mathrm{~g} / \mathrm{L})$ mixture was added and the incubation continued for further $2 \mathrm{~h}\left(37^{\circ} \mathrm{C}, 90 \mathrm{rpm}\right)$. The dialysed intestinal fraction (fraction inside the dialysis membrane), consisting of soluble compounds of low molecular weight, and the non-dialysed intestinal fraction (fraction outside the dialysis membrane), consisting of soluble and insoluble compounds of low and high molecular weight, were collected and placed in a cold water bath for $10 \mathrm{~min}$ to stop intestinal digestion. Bioaccessibility (\%), referred to the percentage of tested compound remaining in the dialysed intestinal fraction related to the original non-digested sample was determined according to Eq. 3 .

$$
\text { Bioaccessibility }(\%)=\frac{\text { Dialysed fraction } \times 100}{\text { Non digested content }}
$$

\section{Statistical analysis}

An analysis of variance (ANOVA) was applied to the results obtained in order to verify whether there were significant differences in the parameters studied in relation to sample analysed, and to ascertain possible interactions between factors (differences at $\mathrm{p}<0.05$ were considered significant). Where there were differences, an LSD (last significant difference) test was applied to indicate the samples in which differences were observed. A multiple regression analysis was performed to study the influence of bioactive compounds to antioxidant capacity (the results are shown in the significant cases, $\mathrm{p}<0.05$ ). Finally, a study was conducted with the aim of determining whether there were correlations between a pair of variables (Pearson's test). All statistical analyses were performed using Statgraphics ${ }^{\circledR}$ Centurion XVI (Statpoint Technologies Inc., USA).

\section{Results and discussion}

Changes in bioactive compounds such as ascorbic acid, total carotenoids, total phenolic content as well as antioxidantcapacity due to high voltage electrical discharges (HVED), pulsed electric fields (PEF) of orange peel were studied. To better compare the effects of non-thermal treatments on bioactive compounds stability and bioaccessibility through an in vitro simulated digestion equivalent energy inputs of $55 \mathrm{~kJ} / \mathrm{kg}$ (PEF 1/HVED1) and 364kJ/kg (PEF 2/ HVED2) were used.

\section{Undigested samples, immediately after PEF, HVED treatments}

Table 1 shows the contents of bioactive compounds and total antioxidant capacity obtained immediately after applying the nonthermal treatments (PEF, HVED) at two equivalent energy inputs (55 and $364 \mathrm{~kJ} / \mathrm{kg}$ ). As it can be observed all factor such as type of treatments as well as energy input had a significant influence in changes, however the extend of improvement or degradation was different.

Table I Content of bioactive compounds and antioxidant capacity of orange peel after different treatments applied.

\begin{tabular}{lllll}
\hline & PEF1 & PEF2 & HVED1 & HVED2 \\
\hline AA $(\mathrm{mg} / 100 \mathrm{~mL})$ & $24.6 \pm 0.9$ & $18.3 \pm 0.9$ & $14.5 \pm 0.9$ & $11.9 \pm 0.9$ \\
TPC $(\mathrm{mg} \mathrm{GAE} / 100 \mathrm{~mL})$ & $95.8 \pm 0.1$ & $456.1 \pm 0.0$ & $184.2 \pm 5.5$ & $692.1 \pm 1.1$ \\
TC $(\mu \mathrm{g} / 100 \mathrm{~mL})$ & - & - & $369.3 \pm 7.1$ & $286.9 \pm 3.5$ \\
TEAC $(\mathrm{mM} \mathrm{TE})$ & $1.3 \pm 0.1$ & $3.5 \pm 0.6$ & $1.2 \pm 0.1$ & $4.7 \pm 0.1$ \\
ORAC $(\mathrm{mM} \mathrm{TE})$ & $1.3 \pm 0.0$ & $3.5 \pm 0.2$ & $1.5 \pm 0.1$ & $5.7 \pm 0.1$
\end{tabular}

TPC, total phenolic content;TC, total carotenoids;TEAC, trolox equivalent antioxidant capacity; ORAC, oxygen radical antioxidant capacity; PEFI, pulsed electric fields (55kJ/kg); PEF2, pulsed electric fields (364kJ/kg); HVEDI, high voltage electrical discharges (55kJ/kg); HVED2, high voltage electrical discharges (364kJ/kg) 
The analysis of ascorbic acid showed a noticeable decrease after HVED treatment which can be explained by the formulation of gaseous cavitation bubbles, as well as shocked of waves of high pressure. ${ }^{16}$ Higher decrease was observed after HVED treatment with higher energy applied, which can be explained by the increase of temperature at high energy levels. Furthermore, we also observed a significant decrease of ascorbic acid after applying PEF treatment with a higher energy input.

On the other hand a significant increase in total phenolic content was found when energy input was augmented for both technologies $(364 \mathrm{~kJ} / \mathrm{kg})$. The highest phenolic content recovery was obtained after applying HVED at $364 \mathrm{~kJ} / \mathrm{kg}$. Moreover, the recovery of phenolic content after PEF was significantly lower compared to HVED at equivalent energy inputs. The values obtained for PEF were in the range to those previously reported by Luengo et al. ${ }^{15}$ who evaluated the effectiveness of PEF on antioxidant compounds applying PEF $(1-7 \mathrm{kV} / \mathrm{cm})$ treatments combined with pressing $(5-30 \mathrm{~min})$ in orange peel.

Total carotenoids decreased significantly when HVED2 was used at $364 \mathrm{~kJ} / \mathrm{kg}(286.9 \mu \mathrm{g} / 100 \mathrm{~mL})$ in comparison with HVED $1(369.3 \mu \mathrm{g} / 100 \mathrm{~mL})$. This fact can be attributed to the formation of chemical products of electrolysis and free reactive radicals, which are able to reduce nutritional quality of high-added value compounds when HVED is applied at high energy inputs. ${ }^{16,26}$ Surprisingly PEF treatments caused a total degradation in carotenoids content. A possible explanation for this phenomenon is that PEF does not affect small cell compartments such as chromoplasts, in which carotenoids are mainly found. ${ }^{27}$

To estimate antioxidant capacity of orange peel two different antioxidant assays; trolox equivalent antioxidant capacity (TEAC) and oxygen radical antioxidant capacity (ORAC) were used. The analysis of antioxidant capacity using both methods (TEAC, ORAC) showed an improvement in antioxidant capacity when higher energy input was applied. In the case of physicochemical properties, there was no difference observed on $\mathrm{pH}$ after different treatments applied (data not shown).

\section{Digestibility of the orange peel extracts treated by two different treatments (PEF, HVED) at equivalent energy inputs}

In order to better compare the effects of (PEF and HVED) treatments on bioactive compounds and antioxidant capacity, bioaccesibility thorough an in vitro simulated digestion was analysed. Three-way ANOVA analysis was performed to evaluate the influence of type of treatment, energy input and step of in vitro digestion on changes in content of bioactive compounds and antioxidant capacity. The analysis regarding ascorbic acid content in orange peel treated by HVED and PEF processing during the simulated gastrointestinal digestion is shown in Table 2. During in vitro gastrointestinal digestion, there was a significant decrease in the ascorbic content observed when treatment with lower energy input $(55 \mathrm{~kJ} / \mathrm{kg})$ was applied. After gastric conditions, the recovery of ascorbic acid was in range of $19.5 \%$ (PEF1) to $83.3 \%$ (HVED2). After the intestinal phase, as well as in the dialyzed fraction, there was no ascorbic acid detected, showing the lability of this vitamin susceptible to factors such as $\mathrm{pH}$, colour, light and temperature, to which samples are subjected during simulated in vitro gastrointestinal digestion.
Table 2 Content of ascorbic acid of orange peel during simulated gastrointestinal digestion after different treatments applied

\begin{tabular}{ll}
\hline & Ascorbic Acid $\mathbf{( m g / 1 0 0 ~} \mathbf{~ L L})$ \\
\hline PEF1 & $24.6 \pm 0.9^{\mathrm{a}}$ \\
Non-digested & $4.8 \pm 0.9^{\mathrm{b}}$ \\
Nastric & - \\
Dialysed fraction & - \\
PEF2 & $18.3 \pm 0.9^{\mathrm{a}}$ \\
Non-digested & $13.2 \pm 0.9^{\mathrm{b}}$ \\
Gastric & - \\
Non-dialysed fraction & - \\
Dialysed fraction & \\
HVED1 & $14.5 \pm 0.9^{\mathrm{a}}$ \\
Non-digested & $4.7 \pm 0.9^{\mathrm{b}}$ \\
Gastric & - \\
Non-dialysed fraction & - \\
Dialysed fraction & $9.9 \pm 0.9^{\mathrm{b}}$ \\
HVED & - \\
Non-digested & \\
Gastric & \\
Non-dialysed fraction & \\
Dialysed fraction & \\
\hline
\end{tabular}

PEFI, pulsed electric fields (55kJ/kg); PEF2, pulsed electric fields (364kJ/kg); HVEDI, high voltage electrical discharges $(55 \mathrm{~kJ} / \mathrm{kg})$; HVED2, high voltage electrical discharges $(364 \mathrm{~kJ} / \mathrm{kg})$

Changes in total phenolic content (TPC) during in vitro gastrointestinal digestion shown Figure 1A \& Figure 1B. TPC content was significantly higher in both cases (PEF, HVED) when energy input was augmented. In addition, the gastric phase revealed nonsignificant modifications in TPC content after gastric digestion in HVED compared to undigested samples. These results are in close agreement to those found by other authors who found that some specific phenolic content from apples appear quite stable after acid hydrolysis in the stomach. ${ }^{28-30}$ After gastric conditions, the recovery of TPC was in range of $92.7 \%$ (PEF 2) to $102 \%$ (HVED 1). Regarding intestinal phase, the application of HVED1 led to a difference in TPC of non-dialysed fraction in comparison to undigested sample. Moreover, a significant decrease was found in TPC of non-dialysed fraction when energy input was augmented PEF 2, HVED 2. This fact can be explained by two reasons: some modifications in the specific compounds extracted when energy input was augmented, and/or the formation of hydroxyl radicals during water photodissociation caused by electrical discharges, ${ }^{16}$ which can reduce the content of these compounds during intestinal phase. The losses which were observed 
in the non- dialysed intestinal being recovery between $35.5 \%$ (HVED 2) to $56.4 \%$ (PEF 1) with respect to dialysed fraction.
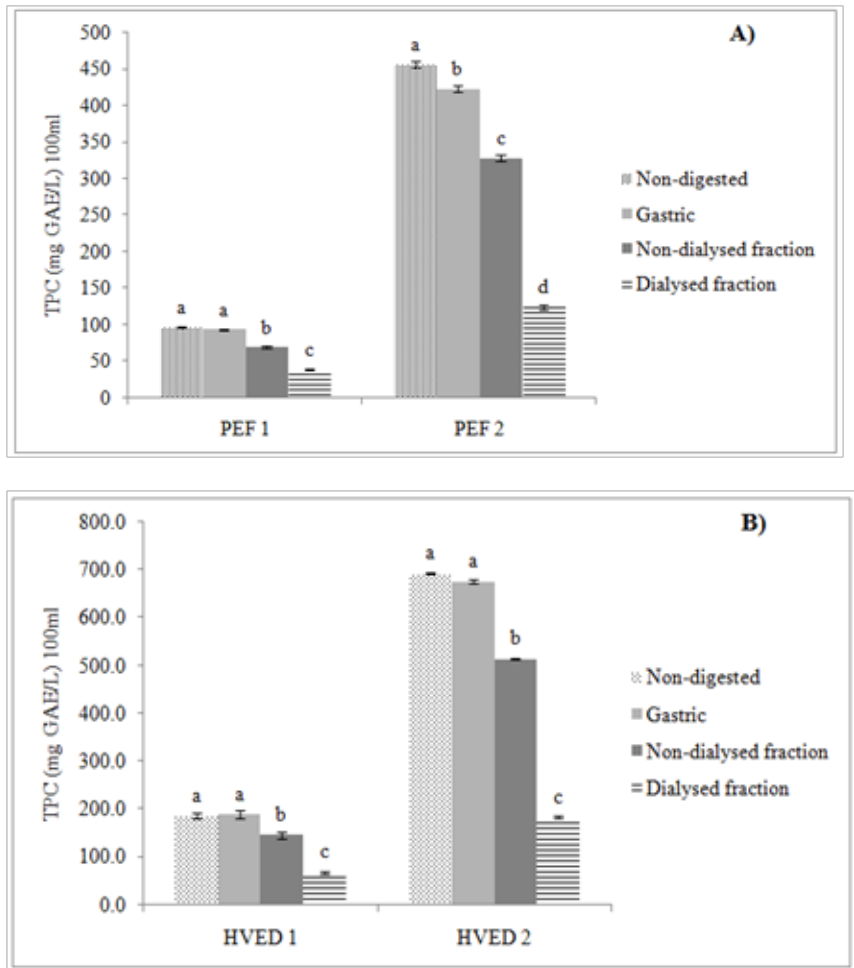

PEFI, pulsed electric fields (55kJ/kg); PEF2, pulsed electric fields (364kJ/kg); HVEDI, high voltage electrical discharges $(55 \mathrm{~kJ} / \mathrm{kg})$; HVED2, high voltage electrical discharges $(364 \mathrm{~kJ} / \mathrm{kg})$

Figure I Content of phenolic compounds (TPC) during simulated gastrointestinal digestion of orange peel after A) pulsed electric fields and B) high voltage electrical discharges

From our analysis PEF 2(37.9\%) and HVED 2(35.5\%) obtain the lowest recovery compared to non-dialysed fraction. Also Boussetta et al., ${ }^{31}$ observed a negative effect of electrical discharges when energy values of $80-800 \mathrm{~kJ} / \mathrm{kg}$ was applied. On the other hand, as can be observed in Figure 2, it was found a significant increase in carotenoid contentduring gastric digestion and non-dialysed fraction for both HVED treatments compared to non-digested samples. The recovery of carotenoids was for HVED1 (109.3\%) and HVED 2(139\%). These results were in close agreement to those reported by Courrad et al..$^{32} \&$ Rich et al. ${ }^{33}$ they observed that lutein and $\beta$-carotene were completely retained or even it was obtained a significant increase in $\beta$-carotene at the end of the digestion. These authors attributed this fact to an improved yield promoted by the different processes involved in matrix disruption, thus facilitating the carotenoid extraction from food matrix. In the non-dialysed fraction we observed a stable recovery HVED 1(60.9\%) and HVED 2(65.1\%), respect to dialysed fraction.

For instance, in another study, it was reported that particle size had a significant influence in carotenoid bioaccessibility from carrot- and tomato-derived suspensions, observing an increase in the bioaccessibility of these compounds when particle size was smaller. ${ }^{34}$ As it was previously reported, HVED is a technology which is based on the fragmentation of food matrix, thus facilitating carotenoid bioaccessibility. Moreover, Moelants et al. ${ }^{34}$ also attributed the increase in bioaccessibility of carotenoids to interactions between compounds of the complex food matrix.

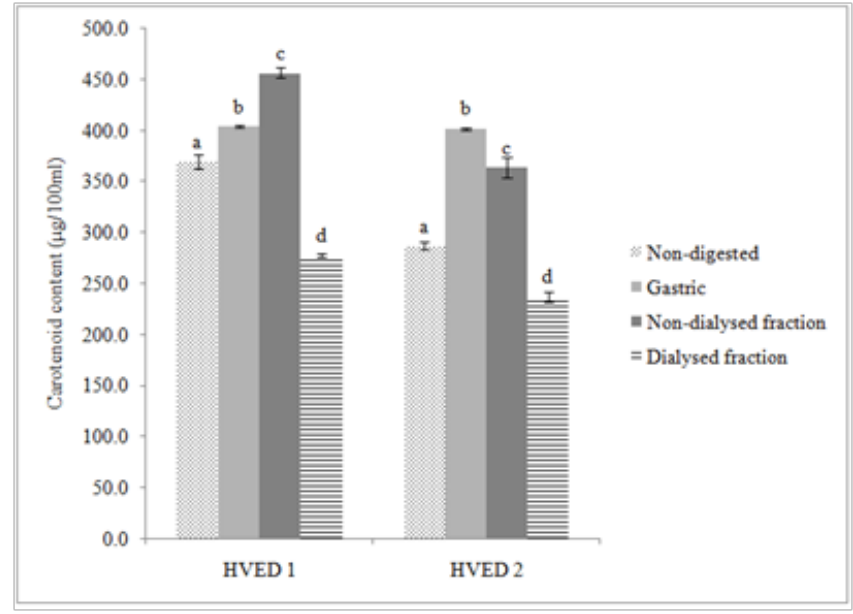

HVEDI, high voltage electrical discharges $(55 \mathrm{~kJ} / \mathrm{kg})$; HVED2, high voltage electrical discharges $(364 \mathrm{~kJ} / \mathrm{kg})$

Figure 2 Content of carotenoids during simulated gastrointestinal digestion of orange peel after high voltage electrical discharges.

The antioxidant capacity (TAC) of orange peel after PEF and HVED treatments was measured by two different methods (TEAC, ORAC). Regarding TEAC measurements (Figure 3) a significant increase in intestinal phase (non-dialysed fraction) in PEF1 and HVED1 treated samples was observed compared to undigested samples. After gastric conditions a recovery of total antioxidant capacity measured with TEAC methods was in range $(61.7 \%$ - $92.3 \%)$. In non-dialysed intestinal digesta, recovery was lowest $(88 \%)$ for HVED2 sample.

Figure 4 shows the contents of the total antioxidant capacity measured with ORAC assay obtained during gastrointestinal digestion after applying two different treatments (PEF, HVED) at two equivalent energy inputs ( 55 and $364 \mathrm{~kJ} / \mathrm{kg}$ ). It shows a significant enhancement of total antioxidant capacity in non-digested samples when both treatments (PEF and HVED) with higher energy input were applied. However the highest value shows HVED-2. The ANOVA analysis shows a significant increase $(\mathrm{p}<0.05)$ in the intestinal tract after simulated digestion when ORAC methods were used. In all treated samples the highest value was detected after treatments with higher energy input applied $(364 \mathrm{~kJ} / \mathrm{kg})$.

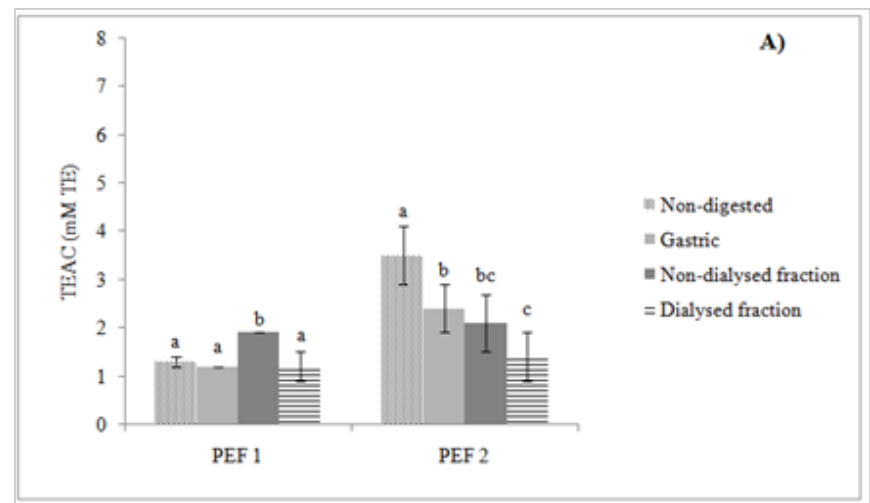




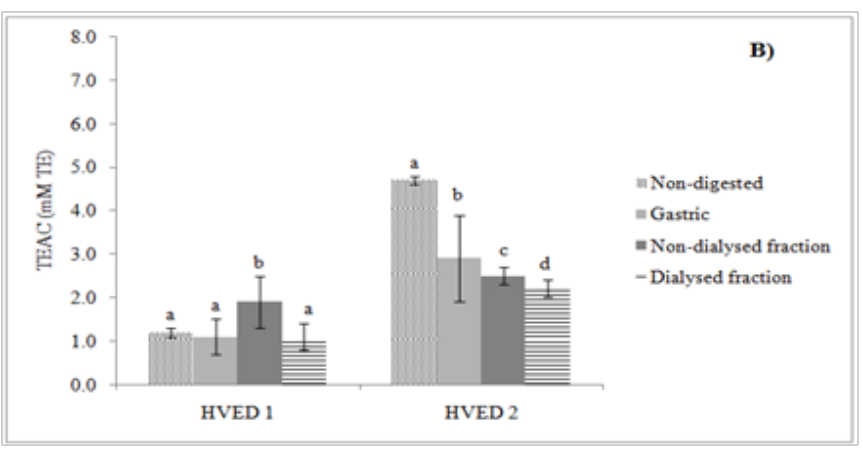

TEAC, trolox equivalent antioxidant capacity; PEFI, pulsed electric fields $(55 \mathrm{~kJ} / \mathrm{kg})$; PEF2, pulsed electric fields $(364 \mathrm{~kJ} / \mathrm{kg}) ; \mathrm{HVEDI}$, high voltage electrical discharges $(55 \mathrm{~kJ} / \mathrm{kg})$; HVED2, high voltage electrical discharges $(364 \mathrm{~kJ} / \mathrm{kg})$

Figure 3 Antioxidant capacity (TEAC values) during simulated gastrointestinal digestion of an orange peel after A) pulsed electric fields (PEF) and B) high voltage electrical discharges (HVED) processing at two energy inputs.

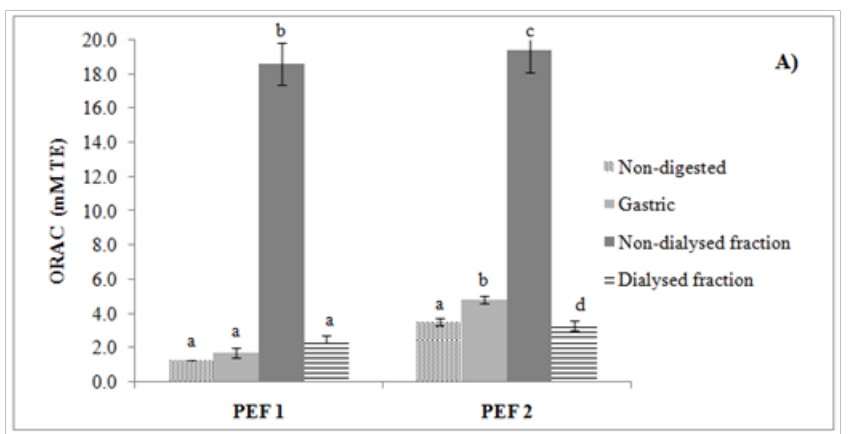

PEFI, pulsed electric fields (55kJ/kg); PEF2, pulsed electric fields $(364 \mathrm{~kJ} / \mathrm{kg}$ ), HVEDI, high voltage electrical discharges $(55 \mathrm{~kJ} / \mathrm{kg})$, HVED2, high voltage electrical discharges $(364 \mathrm{~kJ} / \mathrm{kg})$

Figure 4 Antioxidant capacity (ORAC) during simulated gastrointestinal digestion of an orange peel after A) pulsed electric fields (PEF) and B) high voltage electrical discharges (HVED) processing at two energy inputs.

\section{Bioaccessibility of the orange peel treated by two different treatments (PEF, HVED) at equivalent energy inputs.}

The relative bioaccessibility of bioactive compounds and antioxidant capacity is shown in Figure 5. The bioaccessibility of carotenoids after HVED 1 was $75.3 \%$. On the other hand when increasing the energy input from 55 to $364 \mathrm{~kJ} / \mathrm{kg}$ in HVED the bioaccessibility percentage increased in a $82.5 \%$. Similarly Bengtsson et al. ${ }^{35}$ found that the extraction of $\beta$-carotene from plant structure and the bioaccessibility can be enhanced by treatment. Moreover, Palmero et al. ${ }^{36}$ observed that the intensity of the treatment plays a determined role in terms to obtaining a higher fraction of $\beta$-carotene that is available for absorption.

Regarding TPC bioaccessibility the highest value was observed when PEF at lower energy input was applied (40.7\%). However increasing the energy input to $364 \mathrm{~kJ} / \mathrm{kg}$ led to decrease of the TPC independently of treatment applied. This phenomenon could be explained by the formation of highly reactive chemicals. Bioaccessibility of TAC using two different assays (TEAC, ORAC) was also determined. As can be noted the highest bioaccessibility was obtained in the samples treated by HVED1 and PEF1 independently of the method used. By contrast when higher energy input was applied bioaccessibility decreased significantly for PEF 2(40.5\%), HVED $2(47.9 \%)$ according to TEAC method and PEF 2(65.8\%), HVED $2(39.8 \%)$ for ORAC method.

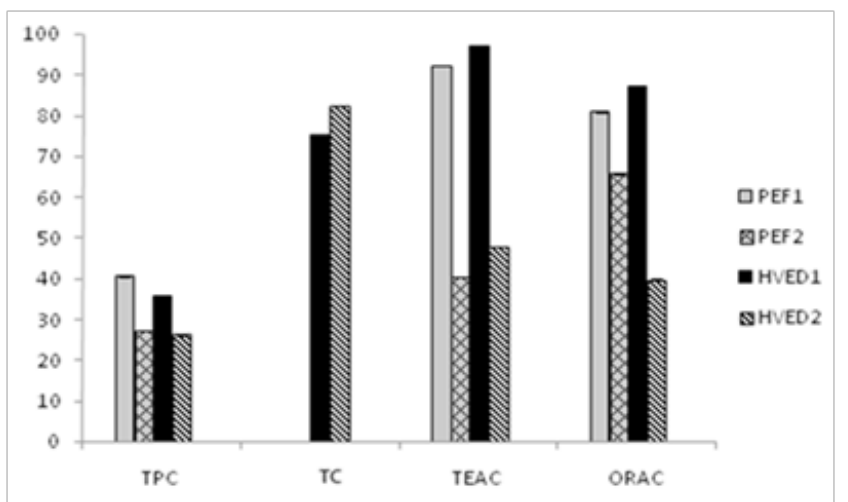

TPC, total phenolic content;TEAC, trolox equivalent antioxidant capacity; TC, total carotenoids; PEFI, pulsed electric fields $(55 \mathrm{~kJ} / \mathrm{kg})$, PEF2, pulsed electric fields $(364 \mathrm{~kJ} / \mathrm{kg})$, HVEDI, high voltage electrical discharges $(55 \mathrm{~kJ} / \mathrm{kg})$, HVED2, high voltage electrical discharges $(364 \mathrm{~kJ} / \mathrm{kg})$

Figure 5 Bioaccessibility of bioactive compounds and antioxidant capacity of orange peel treated by pulsed electric fields (PEF), and by high voltage electrical discharges at two equivalent energy inputs.

\section{Conclusion}

From the results obtained in this study it is possible to conclude that PEF and HVED can be used as a useful tool to recover antioxidant compounds from orange peels. Although HVED led to the higher TPC, carotenoids and TEAC, ORAC yields, PEF treatments at equivalent energy inputs showed the higher TPC and TEAC, ORAC bioaccessibility. So, at this stage of development, there is a need to optimize processing conditions and further studies dealing with this topic are needed.

\section{Acknowledgements}

This research proyect was supported by the Valencian Autonomous Government (Conselleríad'Educació, Cultura I Esport. Generalitat Valenciana) (AICO/2015/083). Buniowska, M. thanks to Podkarpackie Marshals Office for Ph.D. scholarship number (8.2.2/ IV.26/217/11/U/155/12) of RSI Project for Podkarpackie Region, Poland. Carbonell-Capella, J.M. thanks the F.P.U. grant (No.AP20102546) provided by the Spanish Ministry of Education.Authors thank Dr.E. Vorobiev, Dr.N. Grimi and Dr. F. Barba for their help with preparation of sample treatments from Centre de Researches de Royallieu, Université de Technologie de Compiégne.

\section{Conflict of interest}

The author declares no conflict of interest.

\section{References}

1. De Moraes HR, De Castro TAP, Genovese MI. Antioxidant capacity and mineral content of pulp and peel from commercial cultivars of citrus from Brazil. Food Chemistry. 2012;134(4):1892-1898.

2. Jwanny EW, El-Sayed ST, Salem AM, et al. Fractionation, identification 
and biological activities of Egyptian citrus peel extracts. Australian Journal of Basic and Applied Sciences. 2012;6(4):34-40.

3. Karoui JI, Marzouk B. Characterization of bioactive compounds in Tunisian bitter orange (Citrus aurantium L.) peel and juice and determination of their antioxidant activities. Biomed Res Int. 2013;2013:345415.

4. González-Gómez D, Cardoso V, Bohoyo D, et al. Application of experimental design and response surface methodology to optimize the procedure to obtain a bactericide and highly antioxidant aqueous extract from orange peels. Food Control. 2014;35(1):252-259.

5. Abdullah N, Zulkifli KS, Abdullah A, et al. Assessment on the antioxidant and antibacterial activities of selected fruit peels. International Journal of Chem Tech Research. 2012;4(4):1534-1542.

6. Al-Juhaimi FY. Citrus fruits by-products as sources of bioactive compounds with antioxidant potential. PakJ Bot. 2014;46(4):1459-1462.

7. Odriozola-Serrano I, Aguiló-Aguayo I, Saliva-Fortuny R, et al. Pulsed electric fields processing effects on quality and health-related constituents of plant-based foods. Trends in Food Science and Technology. 2013;29(2):98-107.

8. Parniakov O, Lebovka NI, Van Hecke E, et al. Pulsed electric field assisted pressure extraction and solvent extraction from mushroom (Agaricusbisporus). Food and Bioprocess Technology. 2014;7(1):174183

9. Vorobiev E, Lebovka N. Enhanced extraction from solid foods and biosuspensions by pulsed electrical energy. Food Engineering Reviews. 2010;2(2):95-108

10. Chemat F, Vian MA, Cravotto G. Green extraction of natural products: concept and principles. International Journal of Molecular Sciences 2012;13(7):8615-8627.

11. Vorobiev E, Lebovka NI. Pulsed electric field technology for the food industry. Fundamentals and applications. In: J Raso, et al. editors. Food Engineering Series. 2006. p. 153-194.

12. Donsi F, Ferrari G, Pataro G. Applications of pulsed electric field treatments for the enhancement of mass transfer from vegetable tissue. Food Engineering Reviews. 2010;2(2):109-130.

13. Knorr D, Froehling A, Jaeger H, et al. Emerging technologies in food processing. Annual Review of Food Science and Technology. 2011;2:203235

14. Martín-Belloso O, Soliva-Fortuny R. Pulsed electric fields processing basics. In: HQ Zhang, et al. Editors. Non thermal Processing Technologies for Food. USA: Blackwell Publishing Ltd; 2011. p. 155-175.

15. Luengo E, Álvarez I, Raso J. Improving the pressing extraction of polyphenols of orange peel by pulsed electric fields. Innovative Food Science and Emerging Technologies. 2013;17:79-84.

16. Boussetta N, Vorobiev E. Extraction of valuable biocompounds assisted by high voltage electrical discharges: A review. Comptes Rendus Chimie. 2014;17(3):197-203.

17. Cholet C, Delsart C, Petrel M, et al. Structural and biochemical changes induced by pulsed electric field treatments on cabernet sauvignon grape berry skins: Impact on cell wall total tannins and polysaccharides. J Agric Food Chem. 2014;62(13):2925-2934.

18. Tagliazucchi $\mathrm{D}$, Verzelloni $\mathrm{E}$, Bertolini $\mathrm{D}$, et al. In vitro bio-accessibility and antioxidant activity of grape polyphenols. Food Chemistry. 2010;120(2):599-606

19. Carbonell-Capella JM, Barba FJ, Esteve MJ, et al. High pressure processing of fruit juice mixture sweetened with Stevia rebaudiana Bertoni: Optimal retention of physical and nutritional quality. Innovative Food Science and Emerging Technologies. 2013;18:48-56.
20. Georgé S, Brat P, Alter P, et al. Rapid determination of polyphenols and vitamin C in plant-derived products. Journal of Agricultural and Food Chemistry. 2005;53(5):1370-1373.

21. Barba FJ, Cortés C, Esteve MJ, et al. Study of antioxidant capacity and quality parameters in an orange juice-milk beverage after high-pressure processing treatment. Food and Bioprocess Technology. 2012;5(6):22222232.

22. Lee HS, Castle WS. Seasonal changes of carotenoid pigments and color in Hamlin, Earlygold, and Budd Blood orange juices. J Agric Food Chem. 2001;49(2):877-882.

23. Ritter ED, Purcell AE. Carotenoids as colorants and vitamin A precursors. In: Bauernfeind editor. Academic, New York, USA; 1981. p. 815-923.

24. Re R, Pellegrini N, Proteggente A, et al. Antioxidant activity applying an improved ABTS radical cation decolorization assay. Free Radic Biol Med. 1999;26(9-10):1231-1237.

25. Rodríguez-Roque MJ, Rojas-Graü MA, Elez-Martínez P, et al. Changes in vitamin $\mathrm{C}$, phenolic, and carotenoid profiles throughout in vitro gastrointestinal digestion of a blended fruit juice. J Agric Food Chem. 2013;61(8):1859-1867.

26. Parniakov O, Barba FJ, Grimi G, et al. Impact of pulsed electric fields and high voltage electrical discharges on extraction of high-added value compounds from papaya peels. Food Research International. 2014;65:337-343.

27. Schoenbach KH, Joshi RP, Kolb JF, et al. Ultrashort electrical pulses open a new gateway into biological cells. In Proceedings of the IEEE. 2004;92(7):1122-1137.

28. Manach C, Scalbert A, Morand C, et al. Polyphenols: Food sources and bioavailability. American Journal of Clinical Nutrition. 2004;79(5):727747.

29. Bouayed J, Deuser H, Hoffmann L, et al. Bioaccessible and dialysable polyphenols in selected apple varieties following in vitro digestion vs. their native patterns. Food Chemistry. 2012;131(4):1466-1472.

30. Tenore GC, Campiglia P, Ritieni A, et al. In vitro bioaccessibility, bioavailability and plasma protein interaction of polyphenols from Annurca apple (M. pumila Miller cv Annurca). Food Chem. 2013;141(4):35193524 .

31. Boussetta N, Vorobiev E, Deloison V, et al. Valorisation of grape pomace by the extraction of phenolic antioxidants: Application of high voltage electrical discharges. Food Chem. 2011;128(2):364-370.

32. Courraud J, Berger J, Cristol JP, et al. Stability and bioaccessibility of different forms of carotenoids and vitamin A during in vitro digestion. Food Chem. 2013;136(2):871-877.

33. Rich GT, Bailey AL, Faulks RM, et al. Solubilization of carotenoids from carrot juice and spinach in lipid phases: I. Modeling the gastric lumen. Lipids. 2003;38(9):933-945.

34. Moelants KRN, Lemmens L, Vandebroeck M, et al. Relation between particle size and carotenoid bioaccessibility in carrot- and tomato-derived suspensions. J Agric Food Chem. 2012;60(48):11995-12003.

35. Bengtsson A, Brackmann C, Enejder A, et al. Effects on thermal processing on the in vitro bioaccessibility and microstructure of $\beta$-carotene in orange-flashed sweet potato. Journal of Agriculture and Food Chemistry. 2010;58(20):11090-11096

36. Palmero P, Lemmens L, Hendrickx M, et al. Role of carotenoid type on the effect of thermal processing on bioaccessibility. Food Chem. 2014;157:275-282. 